Discussion Considerable numbers of $<16$ year-olds are diagnosed with STIs in GUM clinics in England. Reporting of all these to child protection services would create considerable burdens. Additional risk information from the online tool may provide important evidence of associations between STIs and CSE in order to better use limited resources.

\section{IRIS ADVISE: ASSESSING FOR DOMESTIC VIOLENCE IN SEXUAL HEALTH ENVIRONMENTS (A PILOT STUDY)}

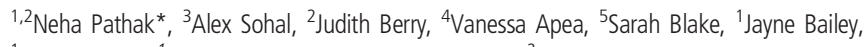
${ }^{1}$ Gene Feder. 'University of Bristol, Bristol, UK; ' $U$ University Hospitals Bristol NHS Foundation Trust, Bristol, UK; ${ }^{3}$ Queen Mary University of London, London, UK; ${ }^{4}$ Barts Health NHS Trust, London, UK; ${ }^{5}$ Next Link, Bristol, UK

\subsection{6/sextrans-2015-052126.13}

Background/introduction Sexual health and gynaecological problems are the most consistent and largest physical health differences between abused and non-abused populations. Sexual health services are well placed to identify and support people experiencing domestic violence and abuse (DVA). Most sexual health professionals have no DVA training despite NICE recommendations. IRIS (Identification and Referral to Improve Safety) is a national GP training intervention that improved the primarycare response to DVA.

Aim(s)/objectives To pilot an IRIS-based training intervention on assessing for domestic violence in sexual health environments (ADViSE), and evaluate its feasibility and effectiveness.

Methods ADViSE was developed and implemented in two sexual health clinics (Site 1 and 2) using a mixed methods design: quantitative analysis of electronic patient records and qualitative analysis of staff interviews, written feedback and anonymised cases. The intervention comprised electronic prompts, multidisciplinary training sessions, clinic materials, and specialised referral pathways to advocate-educators (AE). The pilot lasted 7 weeks at Site 1 and is ongoing at Site 2 to last 12 weeks.

Results Site 1 achieved a $10 \%$ enquiry rate $(\mathrm{N}=267), 6 \%$ disclosure rate $(\mathrm{n}=16)$ and $8 \mathrm{AE}$ referrals. At 8 weeks, Site 2 has achieved a $60 \%$ enquiry rate $(\mathrm{N}=2113)$, a $4.5 \%$ disclosure rate $(\mathrm{n}=90)$ and 9 AE referrals. Staff reported increased confidence in identifying and managing DVA. No DVA cases were recorded in the 3 months preceding the pilots.

Conclusion/recommendations IRIS ADVISE can be successfully developed and implemented in sexual health clinics, fulfilling an unmet need for DVA training. Further evaluation through a larger multicentre study is now necessary.

\section{ATTITUDES TOWARDS HPV VACCINATION FOR BOYS AMONG SEXUAL HEALTH CLINICIANS}

${ }^{1}$ Eleanor Draeger* ${ }^{*}$ 'John McSorley, ${ }^{3}$ Peter Greenhouse, ${ }^{4}$ Janette Clarke. 'Lewisham and Greenwich NHS Trust, London, UK; ${ }^{2}$ London North West Healthcare NHS Trust, London, UK; ${ }^{3}$ Bristol Sexual Health Centre, Bristol, UK; ${ }^{4}$ Leeds Centre for Sexual Health, Leeds, UK

\subsection{6/sextrans-2015-052126.14}

Background In 2014 the JCVI issued an interim position statement recommending HPV vaccination for MSM under 40 through GUM clinics. BASHH advocates universal HPV vaccination.

Aim We sought sexual health clinicians' opinions on HPV vaccination of males.
Methods Online anonymous survey, circulated via BASHH.

Results 131 responses - 90 (68.7\%) female. 95 (75\%) doctors; 19 (14\%) nurses; 8 (6\%) health advisors; 9 (7\%) Other. 117/ $124(95 \%)$ thought there should be universal HPV vaccination. $114 / 118$ (97\%) would vaccinate a daughter, $24 / 27$ (88\%) of those with an eligible daughter had done so. 107/119 (90\%) would vaccinate a son, $10 / 24(42 \%)$ with a teenage son have done so. 118 (90\%) support a catch up programme. 96 (73\%) thought this should include all boys up to age 18. 117 (89\%) thought that MSM and others should also be vaccinated.

\begin{tabular}{|c|c|c|c|}
\hline MSM: Age groups (yrs) & Number (\%) & Other groups & Number (\%) \\
\hline $12-26$ & $41 / 119(34 \%)$ & HIV positive $12-26$ yrs & $36 / 123(30 \%)$ \\
\hline $12-40$ & $16 / 119(13 \%)$ & HIV positive All & 95/123 (78\%) \\
\hline $18-26$ & 3/119 (3\%) & Immunocompromised other & $87 / 123(71 \%)$ \\
\hline $18-40$ & 10/119 (10\%) & Current or past HPV disease & $32 / 123(26 \%)$ \\
\hline All & $49 / 119(49 \%)$ & Screen for HPV types first & $1 / 123(1 \%)$ \\
\hline
\end{tabular}

$65 / 120(54 \%)$ of respondents' clinics are offering (40/120) or plan to offer $(25 / 120)$ HPV vaccine to MSM (Table 1$)$.

Discussion Sexual health clinicians overwhelmingly recommend HPV vaccination of all schoolchildren. They support a targeted HPV vaccination programme in MSM within GUM services but are concerned that this strategy alone is too late and too limited.

\section{IGRA TESTING FOR LATENT TUBERCULOSIS IN COMMERCIAL SEX WORKERS}

${ }^{1}$ Nadia Khatib*, ${ }^{1}$ Ria Daly, ${ }^{1}$ Martin Dedicoat, ${ }^{2}$ Alison Larkins, ${ }^{1}$ Claire Robertson. ${ }^{1}$ Heartlands Hospital, Birmingham, UK; ${ }^{2}$ SAFE Project, Birmingham, UK

\subsection{6/sextrans-2015-052126.15}

Background/introduction Tuberculosis (TB) is a significant public health issue in Birmingham. Targeting 'hard to reach' groups, such as commercial sex workers (CSW), is a priority for Public Health England. Additionally, a large proportion of CSW in Birmingham are from Romania, where TB prevalence is high. We undertook a project to look for latent TB amongst CSW attending an outreach sexual health clinic.

$\operatorname{Aim}(\mathrm{s}) /$ objectives To determine the:

- feasibility of testing and following up this group.

- prevalence of latent TB in this group.

Methods We offered Interferon Gamma Release Assay (IGRA) testing to all CSW attending clinic between 29.04.2014 and 24.11.2014.

Results Seventy-one women were screened. Twenty-six were IGRA positive. Of these, eighteen were followed up in TB clinic:

- Three had results suggesting previous TB and were discharged from clinic without treatment.

- Eleven were diagnosed with latent TB and treated accordingly.

- Four were diagnosed with active TB and are on appropriate therapy.

- Eight were lost to follow up.

Discussion/conclusion We demonstrated that testing is acceptable and feasible to this group. Follow-up was challenging but a review of the referral process led to improved attendance rates. To improve adherence, we used weekly rifapentine and isoniazid 
for latent TB in selected cases. We are the only unit in UK to have used this regimen.

The prevalence rate of latent $\mathrm{TB}$ was higher than anticipated at $15 \%$. Identifying active $\mathrm{TB}$ cases further demonstrated that this is a group worth targeting. These preliminary results led to an extension of this project.

\section{ACCESS TO GUM CLINICS IN THE UK - A WORSENING PICTURE?}

Tim Prescott*, Vanessa Hayden, Elizabeth Foley. University of Southampton, Southampton, UK

\subsection{6/sextrans-2015-052126.16}

Background/introduction In 2004 the Department of Health introduced a mandatory target for $100 \%$ of all patients in England to be offered 48-hour appointments by 2008. In 2010 these targets were removed and in April 2013 further changes to healthcare provision were introduced, with local authorities commissioning GUM (genitourinary medicine) services.

Aim(s)/objectives To assess the effect of recent commissioning changes to the accessibility to GUM clinics.

Methods During November 2014 male and female researchers telephoned all UK GUM clinics that were open for more than one day per week. Researchers contacted clinics twice: firstly presenting with symptoms consistent with an acute sexually transmitted infection and secondly requesting an appointment for an asymptomatic screen.

Results Of 236 clinics contacted, 89\% could accommodate symptomatic 'patients' within $48 \mathrm{~h}$ with $53 \%$ of these on a walk-in basis only. Suggested waiting times ranged between 20 min and $3 \mathrm{~h} .20 \%$ of asymptomatic 'patients' were unable to book an appointment and 58\% of appointments were offered within 48 h. $86 \%$ of asymptomatic 'patients' were offered either a walk in service or appointment within $48 \mathrm{~h}$.

Discussion/conclusion Overall $88 \%$ of 'patients' could be offered a time to be seen in a GUM clinic within $48 \mathrm{~h}$, lower than last year's figure of $95 \%$ and the BASHH standard of $98 \%$, suggesting service access has deteriorated. Further work will include a postal questionnaire to lead clinicians to evaluate their expectations on service access and visits to $33 \%$ of GUM clinics to explore the relationship between suggested waiting times and reality.

\section{WHEN'S BEST TO TEXT? OPTIMUM TIMING OF SMS APPOINTMENT REMINDERS}

Caroline Williams*, Luke Gregory, Ade Apoola, Hayley Wood. Derby Hospitals NHS Foundation Trust, Derby, UK

10.1136/sextrans-2015-052126.17
Background/introduction Throughout healthcare settings 'did not attend' (DNA) rates impact heavily on service efficacy and are estimated to cost the NHS $£ 600 \mathrm{~m}$ per year. Short message service (SMS) texts have been shown to reduce the DNA rates amongst Sexual Health patients.

Aim(s)/objectives The aim of this project was to assess the optimum timing of SMS appointment reminders and its impact on the non-attendance rates in our HIV and Sexual Health service. Methods For three consecutive four week periods between 30/ $12 / 2013$ and $06 / 04 / 2014$, in addition to the routine 'on the day' SMS reminder an extra reminder was sent 1,2 or 3 days prior to patient appointments. Data was collected concerning patient attendances during these periods for pre-booked appointments for HIV and Sexual Health patients. Statistical significance was calculated using Fisher's Exact test and Pearson's correlation coefficient as appropriate.

Results Attendance was monitored for 1,271, 1,215 and 1,264 patients in each 4 week group respectively. Amongst HIV patients, DNA rates fell as the time increased between the appointment and sending the extra SMS reminder. For Sexual Health patients, DNA rates fell as the time was decreased between the appointment and the extra SMS reminder. For both patient groups the gradient of this fall was statistically significant.

Discussion/conclusion This small project has demonstrated the optimum timing of SMS reminders appears different for HIV and Sexual Health patients. HIV patients had lower DNA rates when texted further from the appointment time, whereas Sexual Health patients DNA'd less often if texted nearer to their appointment. Further work is needed confirm the generalisability of our findings and reasons underpinning them.

\section{USE OF A NOVEL QUEUE MANAGEMENT SOFTWARE PROGRAM TO IMPROVE PATIENT SATISFACTION AT A LARGE URBAN GUM CLINIC}

Martina Toby, Cindy Sethi, Anatole Menon-Johansson*. Guys and St Thomas' NHS Foundation Trust, London, UK

\subsection{6/sextrans-2015-052126.18}

Background/introduction Since opening a new clinic there has been high patient flow particularly at weekends. Even with adequate staffing and patients performing self-triage, waiting times sometimes exceed three hours. This frequently resulted in patient aggression towards reception staff, poor patient feedback about waiting times and staff complaints with incident reporting forms (IR1). In October 2014 - new software was introduced to improve patient satisfaction.

Methods Upon entry to the clinic all symptomatic patients were registered on the program which automatically sent a text message informing them of their place in the queue. They were then

\begin{tabular}{|c|c|c|c|c|c|c|c|}
\hline & $\begin{array}{l}\text { DNA Rate SMS sent } \\
1 \text { day prior to } \\
\text { appointment }\end{array}$ & $\begin{array}{l}\text { DNA Rate SMS sent } \\
2 \text { days prior to } \\
\text { appointment }\end{array}$ & $\begin{array}{l}\text { DNA Rate SMS sent } \\
3 \text { days prior to } \\
\text { appointment }\end{array}$ & $\begin{array}{l}1 \text { vs } 2 \text { days } \\
\text { (p) }\end{array}$ & $\begin{array}{l}1 \text { vs } 3 \text { days } \\
\text { (p) }\end{array}$ & $\begin{array}{l}2 \text { vs } 3 \text { days } \\
\text { (p) }\end{array}$ & $\begin{array}{l}\text { Correlation } \\
\text { coefficient } \\
\text { (p) }\end{array}$ \\
\hline HIV Patients & $16.60 \%$ & $16.30 \%$ & $10.24 \%$ & 1.0000 & 0.0483 & 0.0534 & 0.042 \\
\hline Sexual Health Patients & $8.26 \%$ & $9.96 \%$ & $11.16 \%$ & 0.1609 & 0.0167 & 0.3665 & 0.014 \\
\hline
\end{tabular}

